\title{
Dez Anos de Estudos sobre o Sistema de Justiça Brasileiro'
}

Luseni Aquino²

Alexandre Cunha ${ }^{3}$

Bernardo Abreu de Medeiros ${ }^{4}$

\section{INTRODUÇÃO}

A Constituição Federal de 1988 converteu o Judiciário e as "funçóes essenciais à Justiça" (Ministério Público, advocacia pública e privada e Defensoria Pública) em atores de relevo na vida política brasileira. A ampliação de suas atribuiçôes na defesa do interesse público e a diversificação dos instrumentos que lhes permitem atuar sobre os demais Poderes do Estado e a própria sociedade tornaram sua organização e seu funcionamento alvos de acompanhamento e avaliação cada vez mais atentos por parte de pesquisadores e analistas.

A atuação da Diretoria de Estudos e Políticas do Estado, das Instituiçóes e da Democracia (Diest) na temática se insere nesse contexto e, em grande medida, tem representado um reforço importante para os estudos sobre o sistema de justiça, tanto no que se refere à sua consolidação como campo específico de investigaçôes e análises quanto no que diz respeito à produção de insumos para o aprimoramento da prestaçáo de serviços pelos órgáos que compóem o sistema. Este texto apresenta as linhas fundamentais da trajetória de atuação dessa diretoria na área, propondo um breve balanço das principais contribuiçôes aportadas ao debate ao longo dos últimos dez anos.

\section{ANTECEDENTES}

Apesar de as instituições do sistema de justiça terem se tornado objeto de crescente atenção no país logo após a promulgação do novo texto constitucional, os estudos acerca de sua organização, seu funcionamento e seus gargalos eram bastante incipientes antes dos anos 2000. ${ }^{5}$ Aspectos como a ausência de dados sistematizados sobre as diferentes organizaçóes, o fato de que os registros disponíveis se limitavam às movimentaçôes processuais e de que os processos ainda eram, em sua grande maioria, físicos representavam forte limitadores ao desenvolvimento de análises mais profundas e abrangentes, que não podiam prescindir de pesquisas de campo difíceis e complexas. Naquele contexto, as iniciativas eram esparsas e pontuais e tinham cunho eminentemente acadêmico.

Mesmo o processo de Reforma do Judiciário, promovido por meio da Emenda Constitucional no 45/2004 e calcado no binômio eficiência-celeridade, realizou-se em grande medida sob carência de diagnósticos aprofundados acerca do funcionamento do sistema de justiça. Embora a partir de então tenha-se buscado produzir estudos sobre os diferentes órgãos e ramos do sistema, especialmente por meio da Secretaria de Reforma do Judiciário (SRJ), criada em 2003 como parte da estrutura

1. DOI: http://dx.doi.org/10.38116/bapi29art12

2. Técnica de planejamento e pesquisa na Diretoria de Estudos e Políticas do Estado, das Instituições e da Democracia (Diest) do Ipea.

3. Técnico de planejamento e pesquisa na Diest/lpea.

4. Técnico de planejamento e pesquisa na Diest/lpea.

5. Entre os estudos que marcaram o período, destacam-se aqueles realizados por Sadek (1995; 2000; 2001), Arantes (1997), Lopes (2000) e Werneck Vianna et al. (1997). 
do Ministério da Justiça, e do Departamento de Pesquisas Judiciárias (DPJ), do Conselho Nacional de Justiça (CNJ), criado pela Reforma e instalado em 2005, a ausência de dados organizados e confiáveis exigia um trabalho prévio de qualificação das informaçôes produzidas no próprio âmbito do processamento da justiça, ou mesmo a produção de dados primários.

O Ipea não esteve alheio ao crescente interesse pelo sistema de justiça. Mesmo antes da Reforma, alguns esforços de aproximação ao tema foram realizados, embora restritos à abordagem econômica do desempenho do Judiciário e à discussão sobre a segurança jurídica das decisóes judiciais, com foco em seu impacto sobre o chamado "custo Brasil" (Pinheiro, 2003; Banco Mundial, 2004).

Foi no contexto imediatamente posterior à reforma constitucional e infraconstitucional do Judiciário, no entanto, que esses esforços ganharam nova faceta, estabelecendo-se o intento de acompanhar sistematicamente a agenda da Justiça, compreendida como um setor específico da política pública, também denominada política judiciária, e de avaliar as condiçôes de prestação de serviços à população e de promoção do acesso à justiça. É desse período a criação da Coordenação de Justiça e Segurança Pública no âmbito da Diretoria de Estudos e Políticas Sociais (Disoc/Ipea).

Anteriormente, entre 2008 e 2009, a convite do DPJ/CNJ, realizou-se na Disoc um primeiro estudo sistemático sobre um ramo específico do sistema de justiça brasileiro, no caso, a justiça infantojuvenil. Visando apontar critérios a serem observados para o seu aprimoramento, o estudo utilizou, entre outras informaçôes, dados secundários sobre estrutura e movimentação processual já organizados pelo DPJ, e marcou o início de uma parceria institucional que viria a ser duradoura e promissora no desenvolvimento da agenda de estudos sobre o sistema de justiça no Ipea e na futura Diest. O estudo também representou a inauguração de uma forma de atuação fortemente pautada no atendimento a demandas dos órgãos públicos envolvidos no planejamento e na implementação da política judiciária brasileira, notadamente via Ministério da Justiça e órgáos de cúpula do Judiciário.

\section{TRAJETÓRIA DA AGENDA NA DIEST}

\subsection{Novas abordagens para compreender a organização e o funcionamento do sistema de justiça}

Durante o período de instalação da nova diretoria, ${ }^{6}$ o Ipea recebeu, novamente do DPJ/CNJ, a demanda para realizar um estudo sobre o custo das açóes de execução fiscal. Na realidade, o Ipea já havia realizado estudos sobre custos processuais anteriormente, os quais foram calculados a partir da razáo entre o orçamento global do Poder Judiciário e sua produtividade. Entretanto, esse tipo de abordagem ignora a imensa diferença de custo existente entre procedimentos bastante simples, como o da execuçáa fiscal, e extraordinariamente complexos, como o tribunal do júri. O estudo sobre a execução fiscal representava, assim, um duplo desafio. Em primeiro lugar, porque não existia um método consagrado a fim de realizar esse tipo de cálculo, nem no Brasil, nem no exterior. Em segundo, porque a qualidade das informaçôes disponíveis nas bases de dados do sistema de justiça era insuficiente para a realização de um estudo dessa natureza.

Por essas razóes, foi necessário desenvolver uma metodologia específica, baseada em adaptaçóes ao contexto do Judiciário brasileiro dos métodos ABC (Activity-Based Costing) - Custeio Baseado em

6. É importante considerar que a criação da Diest se deu mediante a chegada ao Ipea dos aprovados no concurso de 2008/2009, que mirou a seleção de pessoas com formações diversificadas, entre as quais as diferentes áreas das ciências sociais e ciências sociais aplicadas. Dos novos membros do corpo técnico, alguns tinham formação em direito e logo se uniram a colegas que já atuavam na agenda de estudos e pesquisas sobre o sistema de justiça para constituir, na nova diretoria, a Coordenação de Justiça e Cidadania. 
Atividades - e WCL (Weighted Caseload Method) - Carga de Trabalho Ponderada. Sua aplicação impôs, ainda, em contexto de incipiente organização de dados e virtualização de procedimentos judiciais, a execução de extensivo trabalho de campo para produção das informaçóes não disponíveis nos bancos de dados existentes, por meio do emprego de técnicas de observação, entrevista, mapeamento de processos e análise de autos findos, em amostra nacional de varas judiciais distribuídas espacialmente em mais de cem municípios, de todas as regiōes do país. ${ }^{7}$

Os achados da pesquisa evidenciaram uma realidade que era conhecida apenas de maneira impressionista ou parcial: o processamento da execução fiscal é custoso, envolve em sua maioria açóes de baixo valor e implica, em média, mais de oito anos de tramitação. ${ }^{8}$ A pesquisa gerou importantes repercussões: para a administração pública, proporcionou à Justiça Federal e à Procuradoria-Geral da Fazenda Nacional um conjunto confiável de dados e análises que possibilitou a revisão do modo de atuação do Estado na execução fiscal, gerando ao Tesouro Nacional economias estimadas à época em quase R\$ 1 bilhão anuais; para o Ipea, possibilitou o teste de instrumentos institucionais que, a partir de então, passaram a ser mobilizados por outras áreas para realização de pesquisas de campo.

O êxito da iniciativa levou ao convite, pelo Conselho da Justiça Federal, para que o Ipea avaliasse a experiência de dez anos de implementação dos juizados especiais federais (JEFs) e seus possíveis efeitos sobre as condiçóes de acesso à justiça dos cidadãos brasileiros. Empregando novamente a estratégia de construção de uma pesquisa de campo nacional com atuação em rede, que permitiu visitar, observar, entrevistar atores e analisar autos processuais em amostra nacional de mais de um terço das varas federais existentes no país, a pesquisa possibilitou à equipe o avanço na agenda em torno do tema de acesso à justiça. Entre os resultados produzidos pela pesquisa destaca-se que a maioria dos usuários dos JEFs residia em município diferente da sede do juizado; mais de 85\% eram representados por advogado, embora, em tese, isso não fosse necessário; e o tempo médio de processamento das açóes era de pouco mais de um ano e oito meses, ainda que tramitassem sob o rito mais célere dos juizados. ${ }^{9}$ Esses dados evidenciavam barreiras em termos de acesso aos serviços judiciais e foram bastante importantes para o debate da experiência e o planejamento do sistema de juizados federais, sendo inclusive objeto central do Encontro Anual do Fórum Nacional dos Juizados Especiais Federais, em 2012.

Ambas as iniciativas, implementadas em escala nacional, com base na produção de dados em campo e com a participação de pesquisadores vinculados a outras instituiçóes, consagraram o Ipea como órgão de referência na formação de parcerias interinstitucionais para execução de pesquisas em direito, o que acabaria por resultar na criação da Rede de Estudos Empíricos em Direito (REED), o que ocorreu em agosto de 2011.

\subsection{Consolidação metodológica e ampliação do olhar: sistemas estaduais e matéria penal}

Com a experiência adquirida na pesquisa sobre os JEFs, o trabalho de relevo seguinte se voltou para os juizados especiais cíveis, o que marcou a entrada da Diest no âmbito das justiças estaduais,

7. A complexidade e a novidade da tarefa impuseram a redução do escopo da pesquisa à Justiça Federal, e a realização do trabalho de campo apenas foi possível porque o Ipea vinha desenvolvendo tecnologias institucionais para estabelecimento de parcerias com pesquisadores locais e financiamento de atividades de campo por meio de auxílios financeiros a pesquisadores, que foram pela primeira vez mobilizados para realização de trabalho de campo no âmbito desse projeto.

8. Disponível em: <http://repositorio.ipea.gov.br/handle/11058/887>.

9. Disponível em: <https://www.cjf.jus.br/cjf/corregedoria-da-justica-federal/centro-de-estudos-judiciarios-1/publicacoes-1/pesquisas-do-cej/ acesso-a-justica-federal-dez-anos-de-juizados-especiais>. 
em uma extensão das análises já empreendidas no âmbito federal. Ainda que os estudos anteriores envolvessem a complexidade inerente à pretensão de abrangência nacional, o fato de a Justiça Federal apresentar regras unificadas em todo o país e presença restrita a cidades de médio e grande porte compensava aquela dificuldade. A inclusão da esfera estadual, por seu turno, trouxe novos desafios, uma vez que as justiças estaduais representam 27 realidades distintas, com ampla capilaridade territorial, o que levantava obstáculos logísticos difíceis de ser superados. Assim, optou-se por um recorte que abrangesse apenas três estados da Federação e o Distrito Federal, como objetivo de captar e comparar os arranjos locais e suas implicaçóes quanto ao acesso à justiça, simplicidade e celeridade da prestação jurisdicional. ${ }^{10}$

As dificuldades de acesso enfrentadas pela população chamaram a atenção para as estratégias implementadas com vistas a aproximar o Poder Judiciário dos cidadãos, levando a uma extensão da pesquisa com o objetivo de conhecer melhor as possibilidades e os limites das iniciativas de itinerância, isto é, os projetos nos quais o Judiciário sai das tradicionais estruturas dos fóruns e vai ao encontro da população pelos mais diversos canais. Como o acompanhamento dessas iniciativas requeria presença local continuada, utilizou-se a plataforma Rede Ipea, por meio da qual equipes locais de universidades e institutos de pesquisa se somaram ao projeto. ${ }^{11}$

A experiência obtida na mobilização de redes de pesquisadores, na produção, consolidação e análise de grandes bases de dados, e em temas relativos ao acesso à justiça proporcionou o estabelecimento de nova parceria, desta feita com o Ministério da Justiça e a Associação Nacional dos Defensores Públicos, para execução do Mapa da Defensoria Pública no Brasil. ${ }^{12}$ As fragilidades organizacionais da defensoria pública brasileira constatadas pela pesquisa, bem como obstáculos que se impunham ao acesso à justiça pelos cidadãos brasileiros, informaram a elaboração e a aprovação, pelo Congresso Nacional, da Emenda Constitucional no 80/2014. ${ }^{13}$

Ainda no que concerne à ampliação do escopo dos estudos iniciais, foram desenvolvidos dois projetos centrados na matéria penal: um deles sobre a aplicação de penas e medidas alternativas; ${ }^{14} \mathrm{e}$ outro sobre a questão da reincidência criminal. ${ }^{15}$ Assim, de um olhar voltado quase que exclusivamente para dentro do Poder Judiciário - suas estruturas, rotinas e práticas - passa-se a analisar também seus desdobramentos em uma política concreta e sensível, que é o exercício do poder punitivo do Estado. Frutos de parcerias com o Ministério da Justiça e com o CNJ, os estudos buscaram evidenciar, inicialmente, quais variáveis condicionam a aplicação de pena de prisão ou a sua substituição por medida alternativa. Em certa medida, manteve-se o foco sobre o funcionamento do Poder Judiciário, incluindo a organização dos juizados especiais criminais, as deficiências de pessoal nestas estruturas e as resistências à adoçáo de um rito distinto do tradicional; no entanto, estendeu-se a análise ao Poder Executivo, a quem cumpre tanto manter o sistema prisional como, em muitos casos, coordenar e monitorar o cumprimento das medidas alternativas. Em um segundo momento, avaliou-se como as escolhas quanto ao apenamento podem se refletir na retroalimentação do sistema punitivo, lançando luz sobre a mensuração da reincidência penal no país, uma lacuna até então preenchida com números

10. Disponível em: <http://repositorio.ipea.gov.br/handle/11058/7533>.

11. Disponível em: <http://repositorio.ipea.gov.br/bitstream/11058/7492/1/RP_Democrratiza\%C3\%A7\%C3\%A30_2015.pdf>.

12. Disponível em: <http://repositorio.ipea.gov.br/handle/11058/2419>.

13. A parceria estabelecida em torno desse projeto foi repetida em 2019 para atualização dos dados e análises anteriormente produzidos, bem como para a avaliação dos efeitos decorrentes da nova norma constitucional. 
meramente especulativos. Ambas as etapas foram complementadas com análises qualitativas tanto das estruturas de aplicação e cumprimento de pena como dos perfis dos apenados reincidentes.

\subsection{0 sistema de justiça e a agenda de políticas públicas}

A consolidação da agenda de estudos sobre o sistema de justiça e o amadurecimento das análises realizadas levaram a um desdobramento importante: o desenvolvimento de investigaçóes acerca do impacto dessas instituiçóes sobre diferentes políticas públicas. Em dezembro de 2014, no marco do Protocolo de Rivera, firmado entre a Secretaria Nacional de Políticas sobre Drogas (Senad) do Ministério da Justiça e a Junta Nacional de Drogas do Uruguai (JND), instituiu-se um plano de monitoramento dos efeitos da nova regulamentação uruguaia do mercado de cannabis, política esta que resultou na criação de canais legais de produção, distribuição e comercialização da droga e que potencialmente impactaria diretamente a região de fronteira entre os dois países. O Ipea, que já compunha o Comitê Científico Assessor Internacional da JND, passou a liderar a equipe brasileira responsável pelo acompanhamento da nova política, o qual teve duração de quatro anos. Como resultado desse programa, pesquisadores uruguaios e brasileiros trabalharam cooperativamente na produção de uma série de estudos e diagnósticos sobre a situação na fronteira entre Brasil e Uruguai, inclusive quanto ao processamento criminal em delitos sobre drogas, de modo a manter tecnicamente informadas as autoridades de ambos os países. ${ }^{16} \mathrm{O}$ envolvimento no programa proporcionou ainda uma aproximação entre o Ipea e a Senad, que resultou no desenvolvimento de uma agenda atualmente importante de pesquisas em temas de políticas sobre drogas. ${ }^{17}$

Outro projeto de relevo remete ao tema da judicialização das políticas públicas. No contexto do debate sobre a Reforma da Previdência, a partir de 2016, o Ipea foi instado pela Casa Civil da Presidência da República a executar um estudo sobre as causas de judicialização de benefícios sociais. Como essa judicialização ocorre fundamentalmente por meio dos JEFs, a equipe retomou as reflexôes levantadas a partir de pesquisa anterior, articulando com a Coordenação de Assistência e Previdência Social da Disoc a realização de um estudo focado na trajetória percorrida pelos cidadãos que procuram a justiça para garantir acesso aos benefícios sociais. A partir dos resultados dessa pesquisa a respeito da importância da atuação proativa do poder público na orientação do cidadão, como estratégia para prevenir a judicialização, o Ipea vem assessorando o grupo do Comitê de Monitoramento e Avaliaçáo de Políticas Públicas Federais (CMAP) responsável pela construção de soluçóes para o problema. Também como parte da agenda de reformas implementada a partir de 2016, o Ipea foi convidado pela Justiça do Trabalho a avaliar os efeitos da Reforma Trabalhista de 2017 sobre as condiçóes de acesso à justiça dos trabalhadores, estudo este que se encontra em fase de conclusão.

Fruto de nova parceria institucional com o CNJ, a Diest desenvolveu recentemente um estudo sobre a atuaçáo do Poder Judiciário no enfrentamento à violência doméstica e familiar contra as mulheres, em atendimento às determinações da Lei Maria da Penha (Lei no 11.340/2006). ${ }^{18}$ A pesquisa, também desenvolvida em parceria com a Disoc, evidenciou grande heterogeneidade de atuação, com variaçóes que refletem entendimentos distintos não apenas sobre a própria lei, mas também sobre questôes que vão além do direito, envolvendo concepções e valores ligados às relações

16. Disponível em: <http://repositorio.ipea.gov.br/handle/11058/9941>.

17. Como resultado dessa nova frente, o Ipea participou das negociações em torno da Declaração de Braślia sobre Fronteiras (2016) e vem compondo a delegação brasileira em diferentes encontros das comissões mistas binacionais sobre drogas e delitos conexos entre o Brasil e seus países limítrofes.

18. Disponível em: <http://repositorio.ipea.gov.br/handle/11058/9530>. 
de gênero e ao papel do Judiciário e dos juízes nos casos de violência doméstica. Ademais, mostrou que a especialização na matéria tende a garantir que o atendimento seja mais humanizado, integral e atento às necessidades das mulheres, reforçando, contudo, evidências provenientes de outros estudos quanto ao caráter decisivo do perfil do magistrado à frente da unidade jurisdicional na qualidade dos serviços dispensados.

Finalmente, cabe destacar um projeto desenvolvido por iniciativa da própria Diest para discutir o espaço que as carreiras jurídicas ocupam dentro da estrutura de Estado. Instigado pela percepção da relevância que os atores jurídicos têm na conformação do sistema de justiça e na definição de como este se relaciona com os cidadãos, o projeto, ainda em desenvolvimento, quer disponibilizar um diagnóstico abrangente e sistemático sobre a evolução das carreiras jurídicas e o perfil de seus membros, bem como a evolução dos gastos realizados para remunerá-los. ${ }^{19}$ Dessa maneira, o estudo pretende jogar luz sobre alguns dos efeitos da ampla autonomia administrativa e financeira de que gozam os órgãos do sistema de justiça brasileiro, em especial o Judiciário e o Ministério Público, o que lhes permite, entre outras coisas, desenhar planos de carreira, prover cargos, definir propostas orçamentárias e estabelecer políticas remuneratórias com relativa independência. Busca-se, assim, desvelar um cenário que associa a expansão do número de quadros em patamares superiores aos verificados em outros braços da burocracia estatal ao pagamento de remuneraçóes, benefícios e vantagens diversas em níveis singulares em relação ao serviço público em geral.

\section{CONSIDERAÇÕES FINAIS}

Os estudos sobre o sistema de justiça realizados na Diest ao longo dos últimos dez anos trazem algumas marcas diferenciais. Em primeiro lugar, destaca-se o fato de que a agenda tem se estruturado em torno de demandas que o Ipea recebe de outros órgáos públicos e que versam sobre aspectos variados da organização e do funcionamento de diferentes instituiçóes desse sistema. Em segundo lugar, cabe frisar que, se essa agenda não era exatamente estranha aos trabalhos do instituto anteriores a 2010, sofreu uma inflexão temática fundamental a partir de então, voltando-se à investigação sobre "o fazer diário da justiça” e as condiçôes de acesso disponibilizadas aos cidadãos. E, finalmente, porque a inserção da Diest no cenário mais amplo de pesquisas sobre o sistema de justiça pautou-se por uma forte indução à formação de redes de pesquisadores e grande experimentação metodológica, exigida tanto pelas limitaçôes inerentes aos objetos sob investigação quanto pela abrangência nacional das análises pretendidas.

A trajetória bem-sucedida até aqui gerou importantes legados, com destaque para a consolidação da Coordenação de Estudos sobre Justiça e Cidadania como um espaço de produção científica coletiva e inovadora, engajada na indução e fortalecimento de outros núcleos de pesquisa, tanto acadêmicos quanto institucionais, e na produção de conhecimentos que trazem contribuiçóes diretas para o debate público sobre importantes aspectos do funcionamento do sistema de justiça brasileiro e para o seu aprimoramento. Embora o imenso esforço em construir parcerias institucionais amplas, com o objetivo de executar pesquisas baseadas em metodologias únicas e processos quase artesanais de produção de dados, possa parecer contrário à tendência atual de produção de conhecimento

19. Até o momento, o estudo já ensejou um Texto para Discussão, com análises descritivas acerca da composição das carreiras jurídicas que atuam no âmbito da União e do perfil de seus membros, e um artigo sobre a repercussão do processo de Reforma do Judiciário na configuração dessas carreiras, que compõe publicação da Diest sobre os 25 anos do Plano Diretor da Reforma do Estado. Ambos se encontram em fase de revisão editorial. 
sobre o sistema de justiça, com base em bancos de dados preexistentes e ferramentas de big data, do qual o fenômeno de emergência das lawtechs talvez seja a faceta mais visível, essa perspectiva também não é estranha às atividades desenvolvidas na Diest. Desde 2012 a diretoria vem investindo no desenvolvimento de soluções em tecnologia da informação para consolidação, tratamento e análise de grandes bancos de dados, por meio do sistema denominado IpeaJus. Porém, até o presente momento, o emprego desse tipo de ferramenta ainda não parece capaz de substituir outras estratégias de pesquisa, principalmente em virtude da má qualidade dos dados gerados pelo sistema de justiça brasileiro.

Em termos dos aprendizados, pode-se dizer que, mais do que aportar novos temas à agenda ou responder a problemas teóricos mais amplos, os estudos desenvolvidos na Diest têm se destacado por trazer evidências empíricas para notórios problemas do sistema de justiça, como a morosidade, o alto custo de processamento dos feitos e as barreiras existentes ao acesso da população, os quais estiveram por muito tempo sujeitos a análises parciais e especulativas. Paralelamente, ficou claro ao longo deste percurso que, tais quais institucionalmente sistematizados, os dados produzidos pelo sistema não nos permitem compreender vários aspectos importantes de seu funcionamento. Em outras palavras, trata-se de sistema complexo e pouco transparente, que gera informaçóes que não possibilitam uma reflexão aprofundada sobre a própria qualidade dos dados, limitando a análise a ranqueamentos de tribunais desconectados da discussão ponderada sobre as possíveis causas e soluçôes. Como consequência, o sistema de justiça dificilmente incorpora aprendizados. Os aprimoramentos acabam por ser ocasionais, localizados e dependentes de iniciativas individuais. Assim, ainda que se conforme de maneira industrial, em muitos aspectos se vê como artesanal, e embora "gestáo" seja uma linguagem espraiada, ela não se converte em termos concretos, refém, muitas vezes, de alternâncias bienais da cúpula decisória. Esse cenário ratifica a importância de seguir produzindo informaçóes e análises cada vez mais qualificadas sobre a organização e o funcionamento do sistema de justiça brasileiro, em diálogo tanto com os seus agentes quanto com os atores políticos e acadêmicos que têm se dedicado a contribuir para essa discussão.

Cabe destacar, por fim, assuntos importantes que ficaram fora da agenda de pesquisa da Diest ao longo desses primeiros dez anos, e que constituem desafios relevantes para o futuro da área. Em especial, é de se ressaltar que os estudos passaram ao largo de alguns temas bastante tradicionais nos estudos sobre o sistema de justiça, tais como as questóes relativas à formação de agenda no Poder Judiciário e de sua atuação como poder político, entre as quais a seleção dos grandes temas que têm orientado a política judiciária nacional, a definição das pautas de votação nos tribunais, os aspectos políticos da indicação dos membros das cortes superiores e a prática de lobbying no Judiciário. Igualmente, a ênfase em questóes de acesso à justiça não veio acompanhada da adequada reflexão sobre o dimensionamento do sistema, nem sobre a retórica do "desacesso", articulada em torno à suposta hiperlitigiosidade da sociedade brasileira, temas cujo estudo certamente poderia aportar contribuições importantes do Ipea ao debate público sobre a Justiça do país, evidenciando seus gargalos e apontando perspectivas embasadas para o seu aprimoramento. 


\section{REFERÊNCIAS}

ARANTES, R. B. Judiciário e política no Brasil. São Paulo: EDUC, 1997.

BANCO MUNDIAL. Fazendo com que a justiça conte: medindo e aprimorando o desempenho do judiciário no Brasil. 2004. (Relatório n. 32789-BR).

LOPES, J. A. V. Democracia e cidadania: o novo Ministério Público brasileiro. Rio de Janeiro: Lumen Júris, 2000.

PINHEIRO, A. C. Judiciário, reforma e economia: a visão dos magistrados. Rio de Janeiro: Ipea, 2003. (Texto para Discussão, n. 966).

SADEK, M. T. (Org.). Uma introdução ao estudo da justiça. São Paulo: IDESP; Sumaré, 1995. (Org.). Justiça e cidadania no Brasil. São Paulo: IDESP; Sumaré, 2000.

(Org.). Acesso à justiça. São Paulo: Fundação Konrad Adenauer, 2001.

WERNECK VIANNA, L. et al. Corpo e alma da magistratura brasileira. 2. ed. Rio de Janeiro: Revan, 1997. 